\title{
ADEQUAÇÃO CONSTRUTIVA DA CONFIGURAÇÃO MECÂNICA E DO SISTEMA DE CONTROLE DOS PROTÓTIPOS "LÍBERO" E "MOCHILA" PARA MOTORIZAÇÃO DE CADEIRAS DE RODAS CONVENCIONAIS.
}

\author{
Domenico Di Martino*, Franco G. Dedini.
}

\begin{abstract}
Resumo
Para as pessoas portadoras de alguma deficiência motora nos membros inferiores, a cadeira de rodas representa uma ferramenta fundamental para a sua integração na sociedade, oferencendo a elas maior autonomia e segurança. No entanto, as cadeiras de rodas manuais podem ser díficeis de manobrar, geram fadiga e desconforto para o usuário. Por isso, diversas pesquisas são feitas buscando melhorar a qualidade de vida dos seus usuários. O LabSIn da Faculdade de Engenharia Mecânica trabalha há vários anos para desenvolver soluções que permitam uma motorização simples de cadeiras de rodas comuns. Os protótipos "Líbero" e "Mochila" são resultados desses esforços. O presente trabalho visa construir um novo protótipo que represente um aperfeiçoamento, tanto da parte mecânica quanto do controle, do módulo "Mochila" de forma a melhorar as respostas aos comandos dos usuários.
\end{abstract}

\section{Palavras-chave:}

Mobilidade, cadeira de rodas, motorização.

\section{Introdução}

A cadeira de rodas representa um dos instrumentos mais influentes na vida das pessoas com perda parcial ou total do movimento dos membros inferiores. Nesse aspecto, as cadeiras motorizadas oferecem uma melhor mobilidade e aliviam o esforço exercido pelo usuário. No entanto, devido à sofisticação, elas possuem preços muito elevados. Diversas pesquisas têm sido feitas no intuito de conseguir soluções que ofereçam o conforto de uma cadeira motorizada por um custo mais acessível. Os módulos "Líbero" e "Mochila", desenvolvidos pelo LabSIn, são resultado de tais estudos. O objetivo deste trabalho foi continuar com 0 desenvolvimento destas ideias, construindo um novo protótipo que permita a motorização de cadeiras de rodas convencionais com 0 aprimoramento do conceito dos projetos originais.

\section{Resultados e Discussão}

A partir de um benchmarking de cadeiras de rodas motorizadas no mercado, foram definidos os requisitos esperados do protótipo (Tabela 1).

Tabela 1. Requisitos esperados do protótipo.

\begin{tabular}{|l|c|}
\hline Inclinação máxima suportada & $15^{\circ}$ \\
\hline Velocidade máxima alcançada & $7 \mathrm{~km} / \mathrm{h}$ \\
\hline Velocidade máxima na inclinação máxima & $2 \mathrm{~km} / \mathrm{h}$ \\
\hline Massa do usuário & $50 \mathrm{~kg} \sim 100 \mathrm{~kg}$ \\
\hline
\end{tabular}

Com uma análise das forças envolvidas nas situações de superfícies com inclinação de $0^{\circ}$ e de $15^{\circ}$, considerando-se os requisitos já definidos, obtiveram-se as características mínimas necessárias dos motores de corrente contínua a serem utilizados (Tabela 2).

Tabela 2. Características necessárias dos motores.

\begin{tabular}{|l|c|}
\hline Torque de stall & $2,33 \mathrm{~N} . \mathrm{m}$ \\
\hline Potência máxima & $58 \mathrm{~W}$ \\
\hline Rotação máxima (sem carga) & $954 \mathrm{RPM}$ \\
\hline
\end{tabular}

Assim, foram escolhidos dois conjuntos de motor e redução utilizados em parafusadeiras Makita 8271D, alimentados por duas baterias $12 \mathrm{~V}$ ligadas em paralelo. Optou-se por utilizar uma shield, acoplada a um Arduino, possuindo as pontes $\mathrm{H}$ e uma realimentação da corrente dos motores, permitindo implementar o controle de torque, garantindo o controle da aceleração e do jerk da cadeira de rodas.

Posteriormente, a partir do modelo CAD de uma cadeira de rodas padrão, foi obtida uma aproximação do seu CG. Além disso, com os resultados da pesquisa de SWEARINGEN (1962), obtiveram-se as aproximações para o CG de uma pessoa sentada. Com esses dados, realizaram-se as análises estática e dinâmica do sistema para as situações de subida, descida e posicionamento lateral em superfície com inclinação de $15^{\circ}$. O resultado dessas análises foi uma região de valores possíveis para - CG do protótipo, na qual o sistema seria estável em qualquer inclinação de até $15^{\circ}$.

A transmissão de torque ás rodas traseiras é realizada pelo contato direto de coxins de borracha ligados aos motores e o protótipo é posicionado atrás do encosto da cadeira. Para garantir uma transmissão eficiente, é preciso de ao menos $90 \mathrm{~N}$ de força normal nesse contato. Portanto, utilizou-se 0 príncipio da alavanca, posicionando as baterias a 4 vezes a distância do contato da transmissão até um eixo de pivotamento, sendo esse o valor máximo possível que garante um CG do protótipo dentro da região de estabilidade. Este pivotamento também determina o funcionamento manual ou motorizado da cadeira, dependendo da sua posição.

\section{Conclusões}

Este trabalho especificou os requisitos do projeto e propôs modificações mecânicas no módulo "Mochila" para que eles fossem atendidos em um novo protótipo, levando em conta o conceito do produto: alternativa simples, de baixo custo e que possibilite facilmente a transição entre o modo manual e o motorizado.

\section{Agradecimentos}

Ao CNPq e à PRP-UNICAMP, ao programa PIBIC pela bolsa de auxílio, ao LabSIn pela estrutura e suporte de seus profissionais.

\footnotetext{
${ }_{1}^{1}$ Alvarenga, F.B.; Dedini, F.G. Product (IGDP), v.2, p.59-71, 2004

2 Becker, M. Aplicação de Tecnologias Assistivas e Técnicas de Controle em Cadeiras de Rodas Inteligentes. 2000. 136p. Tese (Doutorado) - Faculdade de Engenharia Mecânica, Universidade Estadual de Campinas, Campinas.

${ }^{3}$ Swearingen, J.J. Determination of centers of gravity of man. Rep Civ Aeromed Res Inst US. United States, 1962 Aug; 62(14):1-37.
} 